\title{
Virological diagnosis of herpes simplex encephalitis in Glasgow (1962-71)
}

\author{
Constance A. C. Ross \\ Regional Virus Laboratory, Ruchill Hospital, Glasgow G20 9NB
}

DURING the 10-year period 1962-1971 a 'firm' diagnosis of herpes encephalitis was made in twenty patients in the West of Scotland on the basis of histological evidence of encephalitis along with isolation of virus from brain and/or serological findings indicative of a current herpes simplex infection. A diagnosis of 'probable' herpes simplex encephalitis was made in an additional eighteen patients with encephalitis (from seventeen of whom no brain material was obtained) on the basis of rising antibody titres to herpes simplex.

\section{'Firm' infections (Table 1)}

Brain biopsy. Specimens of brain were received for virological tests from eighteen (sixteen biopsy and two necropsy) of the twenty patients with a 'firm' diagnosis. Herpes simplex virus was isolated from fourteen of these eighteen, a cytopathic effect typical of herpes simplex virus being obtained in tissue cultures of human lung fibroblasts in 2-4 days, mean 2.7 days. All virus isolations were subsequently confirmed as herpes simplex by neutralization tests. Virus was isolated from some patients with herpes simplex serum antibody, occasionally at high titre, e.g. case J.O.,titre of 128 and case M.H., titre $\geqslant 1024$. Serum antibody does not therefore appear to inhibit isolation of herpes simplex virus from brain extracts.

$C S F$. Attempts at virus isolation from specimens of CSF were unrewarding (no virus was isolated from specimens from nine of these patients).

\section{Techniques for rapid diagnosis}

Fluorescent antibody. This was carried out by the indirect technique on impression smears of brain

TABLE 1. Herpes encephalitis, firm diagnosis (1962-71)

\begin{tabular}{|c|c|c|c|c|c|c|c|c|c|c|}
\hline \multirow[b]{2}{*}{ Case } & \multirow[b]{2}{*}{$\begin{array}{c}\text { Sex } \\
\text { and } \\
\text { age } \\
\text { (years) }\end{array}$} & \multicolumn{4}{|c|}{ Virus } & \multicolumn{3}{|c|}{ Serology } & \multirow[b]{2}{*}{$\begin{array}{l}\text { Treat- } \\
\text { ment } \\
\text { (idox- } \\
\text { uridine) }\end{array}$} & \multirow[b]{2}{*}{ Outcome } \\
\hline & & $\begin{array}{l}\text { virus } \\
\text { iso- } \\
\text { lation } \\
\text { (brain) }\end{array}$ & $\begin{array}{l}\text { virus } \\
\text { iso- } \\
\text { lation } \\
\text { (CSF) }\end{array}$ & $\begin{array}{c}\text { FA } \\
\text { brain } \\
\text { (smears) }\end{array}$ & $\underset{\text { brain }}{\mathbf{E M}}$ & $\begin{array}{l}\text { Day of } \\
\text { illness }\end{array}$ & $\begin{array}{c}\text { Herpes simplex } \\
\text { CF titres } \\
\text { acute/conv. }\end{array}$ & $\begin{array}{l}\text { Var-zoster } \\
\text { CF titres } \\
\text { acute/conv. }\end{array}$ & & \\
\hline $\begin{array}{l}\text { A.McF. } \\
\text { A.McF. } \\
\text { G.W. }\end{array}$ & $\begin{array}{l}\text { M } 3 \\
\text { M } 6 \\
\text { M12 }\end{array}$ & $\begin{array}{l}-\mathbf{B} \\
-\mathbf{N} \\
+\mathbf{B}\end{array}$ & $\begin{array}{l}\text { ND } \\
\text { ND } \\
\text { ND }\end{array}$ & $\begin{array}{l}- \\
- \\
-\end{array}$ & $\begin{array}{l}-\mathrm{Ex} \\
-\mathrm{Ex} \\
-\mathrm{Ex}\end{array}$ & $\begin{array}{l}40 / 52 / 3 \text { year } \\
4 / 15\end{array}$ & $\begin{array}{l}\text { s } 4096 / 4096 / 128 \\
<8 / \geqslant 1024\end{array}$ & $\begin{array}{l}64 / 64 \\
<8 / \geqslant 1024\end{array}$ & $\begin{array}{l}- \\
+\end{array}$ & $\begin{array}{l}\text { Slow deterioration } \\
\text { Fatal at } 6 \text { years old } \\
\text { Recovery with } \\
\text { moderate p.d. }\end{array}$ \\
\hline $\begin{array}{l}\text { F.N. } \\
\text { F.Mc. } \\
\text { E.M. } \\
\text { R.A. }\end{array}$ & $\begin{array}{l}\text { M13 } \\
\text { F14 } \\
\text { F16 } \\
\text { M16 }\end{array}$ & $\begin{array}{l}+\mathbf{B} \\
\text { ND } \\
+\mathbf{B} \\
+\mathbf{B}\end{array}$ & $\begin{array}{l}\overline{N D} \\
\overline{N D}\end{array}$ & $\begin{array}{l}- \\
\text { ND } \\
+ \\
\text { ND }\end{array}$ & $\begin{array}{l}+\mathbf{S} \\
\text { ND } \\
\text { ND } \\
\text { ND }\end{array}$ & $\begin{array}{l}7 / 22 \\
23 / 30 \\
6 / 16 \\
8 / 19\end{array}$ & $\begin{array}{l}32 / 512 \\
2048 / 2048 \\
<8 / 256 \\
16 / 1024\end{array}$ & $\begin{array}{l}<8 / 64 \\
256 / 256 \\
<8 /<8 \\
256 / 256\end{array}$ & $\begin{array}{l}+ \\
- \\
+ \\
+\end{array}$ & $\begin{array}{l}\text { Recovery, complete } \\
\text { Recovery, complete } \\
\text { Fatal } \\
\text { Recovery with } \\
\text { minimum p.d. }\end{array}$ \\
\hline $\begin{array}{l}\text { C.G. } \\
\text { R.B. } \\
\text { C.P. }\end{array}$ & $\begin{array}{l}\text { F17 } \\
\text { M18 } \\
\text { F19 }\end{array}$ & $\begin{array}{l}+\mathbf{B} \\
+\mathbf{B} \\
-\mathbf{B}\end{array}$ & $\begin{array}{l}- \\
\text { ND }\end{array}$ & $\begin{array}{l}- \\
\text { ND }\end{array}$ & $\begin{array}{l}+\mathbf{S} \\
+\mathbf{S} \\
-\mathbf{S}\end{array}$ & $\begin{array}{l}7 / \\
5 / 16 \\
8 / 26\end{array}$ & $\begin{array}{l}<8 / \\
16 / \geqslant 512 \\
256 / 1024\end{array}$ & $\begin{array}{l}<8 / \\
<8 / 8 \\
<8 / 128\end{array}$ & $\overline{-}$ & $\begin{array}{l}\text { Fatal } \\
\text { Fatal } \\
\text { Recovery with } \\
\quad \text { severe p.d. }\end{array}$ \\
\hline $\begin{array}{l}\text { J.L. } \\
\text { C.S. } \\
\text { H.R. } \\
\text { B.C. } \\
\text { M.H. } \\
\text { J.O. }\end{array}$ & $\begin{array}{l}\text { M21 } \\
\text { F23 } \\
\text { F34 } \\
\text { F38 } \\
\text { F41 } \\
\text { M44 }\end{array}$ & $\begin{array}{l}-\mathbf{N} \\
-\mathbf{B}, \mathbf{N} \\
\mathbf{N D} \\
+\mathbf{B} \\
+\mathbf{B} \\
+\mathrm{B}\end{array}$ & $\begin{array}{l}\overline{N D} \\
\text { ND } \\
\overline{N D} \\
-\end{array}$ & $\begin{array}{l}\text { ND } \\
- \\
\text { ND } \\
+ \\
+ \\
-\end{array}$ & $\begin{array}{l}\text { ND } \\
- \\
+ \text { S } \\
\text { ND } \\
\text { ND } \\
\text { ND }\end{array}$ & $\begin{array}{l}4 / 10 \\
5 / 12 \\
5 / \\
7 / \\
10 / \\
7 / 47\end{array}$ & $\begin{array}{l}16</ 512 \\
<8 / 16 \\
32 / \\
8 / \\
\geqslant 1024 / \\
128 / 1024\end{array}$ & $\begin{array}{l}\text { ND } \\
16 / 16 \\
\text { ND/ } \\
<8 / \\
256 / \\
<8 /<8\end{array}$ & $\begin{array}{l}- \\
+ \\
\overline{+} \\
+ \\
+\end{array}$ & $\begin{array}{l}\text { Fatal } \\
\text { Fatal } \\
\text { Fatal } \\
\text { Fatal } \\
\text { Fatal } \\
\text { Recovery with } \\
\quad \text { moderate p.d. }\end{array}$ \\
\hline $\begin{array}{l}\text { J.D. } \\
\text { W.L. } \\
\text { R.M. } \\
\text { M.A. } \\
\text { J.C. }\end{array}$ & $\begin{array}{l}\text { M45 } \\
\text { F52 } \\
\text { M57 } \\
\text { F60 } \\
\text { F63 }\end{array}$ & $\begin{array}{l}+\mathbf{B} \\
+\mathbf{B} \\
+\mathbf{B} \\
+\mathbf{B} \\
+\mathbf{N}\end{array}$ & $\begin{array}{l}- \\
\text { ND } \\
\overline{N D} \\
\text { ND }\end{array}$ & $\begin{array}{l}\overrightarrow{+} \\
\overrightarrow{N D} \\
\text { ND }\end{array}$ & $\begin{array}{l}\text { ND } \\
- \text { Ex } \\
- \text { Ex } \\
+ \text { Ex } \\
\text { ND }\end{array}$ & $\begin{array}{l}7 / 15 \\
10 / \\
6 / 22 / 31 \\
\text { No sera } \\
\text { No sera }\end{array}$ & $\begin{array}{l}<8 / 256 \\
16 / \\
32 / 128 / 256 \\
\text { ND } \\
\text { ND }\end{array}$ & $\begin{array}{l}<8 / 16 \\
<8 / \\
<8 /<8 /<8 \\
\text { ND } \\
\text { ND }\end{array}$ & $\begin{array}{l}+ \\
+ \\
+ \\
+ \\
-\end{array}$ & $\begin{array}{l}\text { Fatal } \\
\text { Fatal } \\
\text { Recovery, complete } \\
\text { Fatal } \\
\text { Fatal }\end{array}$ \\
\hline
\end{tabular}

ND, not done; B, biopsy; N, necropsy; Ex, extract; S, section; p.d., psychomotor defect. 
TABle 2. Herpes encephalitis (1962-71)

\begin{tabular}{lcccccccccc}
\hline & \multicolumn{7}{c}{ Age (years) } & & & \\
Diagnosis & -5 & -10 & -15 & -20 & -30 & -40 & -50 & $50+$ & Totals & Deaths \\
\hline 'Firm' & 1 & 0 & 3 & 5 & 2 & 2 & 3 & 4 & 20 & 13 \\
'Probable' & 3 & 3 & 1 & 0 & 4 & 2 & 2 & 4 & 19 & 2 \\
\hline Totals & 4 & 3 & 4 & 5 & 6 & 4 & 5 & 8 & 39 & 15 \\
\hline
\end{tabular}

biopsy material. Specific immunofluorescence was detected in only four out of ten specimens from which virus was isolated; in one of these four (M.H.) high serum antibody levels did not inhibit fluorescence.

Electron microscopy. Our laboratory does not have an electron microscope so this examination was only available on five brain extracts; only one showed herpes group particles. Electron microscopy on sections from five of the patients (Harland, Adams \& McSeveney, 1967) was more rewarding, four of the five being positive; however, this latter procedure was done only on brains which had been stored in formalin from 3 weeks to 5 years, and therefore did not contribute to a rapid diagnosis.

\section{Serological diagnosis}

A rise in antibody titre to herpes simplex was obtained in eleven of these twenty patients, and three patients showed high but not rising titres $(\geqslant 1024)$. Of the remaining six patients, five died before the second serum could be collected; from one no sera were received. These serological results indicate that when brain biopsy is not available serological antibody tests on paired sera will generally make a 'probable' diagnosis. Difficulties occasionally arise from serological cross-reactions between herpes simplex and varicella-zoster, since heterologous as well as homologous antibody responses are sometimes obtained in patients with past infection with the heterologous virus. Thus, of the eleven patients with rising titres to herpes simplex four $(36 \%)$ also showed rising titres to varicella-zoster, the most marked rises being in the two youngest patients who had probably experienced the most recent varicella-zoster virus infections. Varicellazoster infections can in the same way cause a rise in herpes simplex CF antibody but not a significant increase in neutralizing antibody (Ross, SubakSharpe \& Ferry, 1965; Schmidt, Lennette \& Magoffin, 1969). If, in the absence of virus isolation from brain, a rise in CF antibody is obtained for both herpes simplex and varicella-zoster, neutralization tests for herpes simplex will show a rise in titre in herpes simplex infections but not in varicella-zoster infections.

\section{Age (Table 2)}

Of the twenty patients with a 'firm' diagnosis thirteen died; only three made a complete recovery. Of these twenty only one was under 10 -years-old (A.McF., presenting atypically as a subacute infection). The peak number of eight infections were in patients from 10- to 20-years-old; three of these eight died (all three between 15- and 19-years-old).

Of nineteen 'probable' infections two died (a male of 35 years and a female of 28 years); however, fromo the clinical data we received about these probable cases, many did not recover completely but had neurological deficits. In contrast with the 'firm' diagnosis patients none of those with a 'probable' diagnosis were in the 15-20 year age-group, suggesting that herpes encephalitis in this age-group is especially acute and severe.

\section{References}

Harland, W. A., Adams, J. H. \& McSeveney, D. (1967) Herpes simplex particles in acute necrotizing encephalitis. Lancet, ii, 581.

Ross, C. A. C., Subak-Sharpe, J. H. \& Ferry, P. (1965) Antigenic relationship of varicella-zoster and herpes simplex. Lancet, ii, 708.

Schmidt, N. J., LennetTe, E. H. \& Magoffin, R. L. (1969) Immunological relationship between herpes simplex and varicella-zoster viruses demonstrated by complementfixation, neutralization and fluorescent antibody tests. Journal of General Virology, 4, 321. 